\title{
Aplikasi Pengarsipan Shipper Barang pada Counter JNE Bukit Kapur
}

\author{
Gellysa Urva ${ }^{1}$, Tina Wati Manalu ${ }^{2}$ \\ 1) Program Studi Teknik Informatika, Sekolah Tinggi Teknologi Dumai \\ Jl. Utama Karya Bukit Batrem II \\ Email: gellysa.urva@gsmail.com
}

\begin{abstract}
ABSTRAK
Arsip mempunyai peranan yang sangat penting dalam sebuah instansi atau perusahaan karena digunakan untuk mendukung proses administrasi atau kegiatan yang dilakukan diperusahaan. Apabila arsip yang dimiliki kurang baik pengelolaannya dapat mengakibatkan sulitnya menemukan informasi yang telah disimpan dan akhirnya dapat menghambat tahapan proses pekerjaan selanjutnya. Oleh karena itu sebaiknya arsip dikelola menggunakan sistem pengelolaan arsip yang baik dan benar.Pada penelitian ini dibahas bagaimana merancang, menerapkan sistem serta pemeliharaan dan keamanan dokumen sehingga terhindar dari kerusakan. Sistem dibuat dengan menggunakan aplikasi php mysql dengan tujuan pengarsipan dokumen ini untuk membantu dan mencegah proses yang sangat lama dalam penyimpanan maupun pencarian suatu dokumen yang dibutuhkan diwaktu yang cepat, tepat dan terperinci. Oleh karena itu, Aplikasi ini sangat membantu pihak Counter JNE Bukit Kapur dalam melakukan pekerjaan dengan efektif dan efesien. Berdasarkan pembahasan pengarsipan data pengirim pada Counter JNE Bukit Kapur peneliti berharap sistem yang dibuat membantu dan memudahkan admin dalam dalam mendata dan mengecek barang milik shipper pada Counter JNE Bukit Kapur serta mencetak laporan terperinci
\end{abstract}

Kata kunci: Aplikasi, Arsip, Barang

\begin{abstract}
Archives have a very important role in an agency or company because they are used to support administrative processes or activities carried out in the company. If the archives that are owned are not properly managed, it can make it difficult to find information that has been stored and can eventually hinder the next stage of the work process. Therefore, archives should be managed using a good and correct archive management system. This study discusses how to design, implement a system and document maintenance and security so as to avoid damage. The system is made using the php mysql application with the aim of archiving this document to help and prevent a very long process of storing and searching for a document that is needed in a fast, precise and detailed time. Therefore, this application is very helpful for the JNE Bukit Kapur Counter in doing work effectively and efficiently. Based on the discussion of archiving the sender's data at the Bukit Kapur JNE Counter, the researchers hope that the system created helps and makes it easier for admins to record and check shipper's goods at the Bukit Kapur JNE Counter and print detailed reports
\end{abstract}

Keywords: Aplication, Archives, Stuff 


\section{Pendahuluan}

Perkembangan bidang teknologi saat ini berdampak pada perekonomian Indonesia terutama pada bidang industri jasa. Hal ini terkait dengan semakin maraknya bisnis jual beli online yang dilakukan oleh pelaku usaha online yang terdiri dari masyarakat maupun perusahaan-perusahaan toko online. Bisnis jual beli online membutuhkan jasa pengiriman paket untuk mengantarkan barang dari toko online kepada konsumen dengan cepat, mudah dan aman baik didalam kota, luar kota maupun luar Pulau.

Counter JNE Bukit Kapur merupakan salah satu perusahaan pengiriman dan logistik yang berada di Kota Dumai, melayani jasa pengiriman barang, dokumen, pengiriman belanja online (E-commerce) dan lainnya. Pengarsipan paket barang datang di Counter JNE Bukit Kapur selama ini admin masih menulis atau mencatat ke dalam buku besar sehingga kesalahan dalam meletakkan buku dan mengingat tanggal pengiriman barang sering terjadi karena admin harus bolak-balik membuka buku untuk mencari rekam jejak. Untuk memudahkan admin dalam pencarian data barang milik shipper di Counter JNE Bukit Kapur maka perlu adanya Aplikasi pengarsipan yang dapat mengolah data.

Aplikasi adalah suatu bagian dari perangkat lunak yang dapat digunakan untuk menyelesaikan masalah-masalah yang khusus yang dihadapi user dengan menggunakan kemampuan komputer (Listianto, 2017). Menurut kamus besar bahasa Indonesia arsip /ar-sip/ dokumen (surat, akta dan sebagainya), lisan (pidato, ceramah, dan sebagainya), atau bergambar foto, film, dan sebagainya) dari waktu yang lampau, disimpan dalam media tulis (kertas), elektronik (pita kaset, pita video, disket computer, dan sebagainya), biasanya dikeluarkan oleh instansi resmi, disimpan dan dipelihara ditempat khusus untuk referensi, untuk pembakuan, pengaturan, dan pengawetan yang diperlukan supaya bahan arsip dapat dikenal dan disusun sebagaimana aslinya tanpa ada yang dirusak dan di ubah (Simangungsong, 2018). Barang adalah sesuatu barang atau produk yang ditawarkan dipasaran untuk dapat dimiliki, dipakai dan dikonsumsi oleh konsumen untuk memenuhi kebutuhannya. (Nurhayati, 2018)

\section{Metode Penelitian}

Metode penelitian adalah langkah yang dimiliki dan dilakukan oleh peneliti dalam rangka untuk mengumpulkan informasi. Adapun kerangka kerja yang peneliti lakukan dapat dilihat dari gambar dibawah ini.

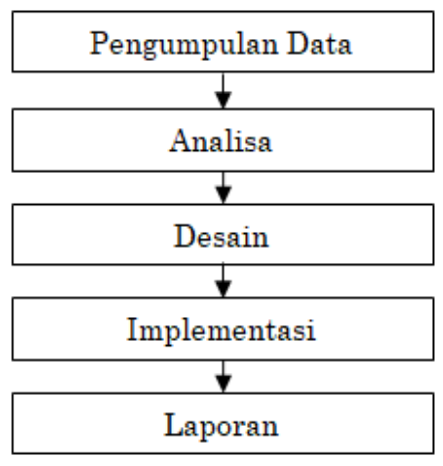

Gambar 1 Kerangka Kerja 
Pada penelitian ini, peneliti akan mengansistem yang akan dirancang menggunakan UML (Unified Modelling Language), yang menggambarkan aliran sistem secara menyeluruh mulai dari user yang terkait sampai kepada aktivitas dan input yang dilakukan pada sistem. Tahap - tahap pemodelan dalam analisis tersebut yaitu Use Case Diagram, Activity Diagram, Sequence Diagram.

\section{Hasil dan Pembahasan}

Use case diagram merupakan suatu bentuk diagram yang menggambarkan fungsional Pengguna terhadap sistem. Pada gambar dibawah ini dapat dijelaskan bahwa ketika admin akan masuk kedalam sistem admin diwajibkan untuk login terlebih dahulu ketika sudah login masuk ke menu utama lalu memilih menu-menu yang ada.

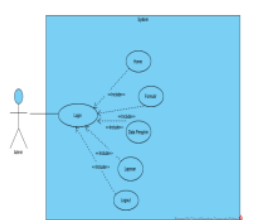

Gambar 2 Use Case Diagram

Pada pembuatan sebuah sistem diperlukan sebuah gambar yang dapat menjelaskan alur atau langkah-langkah dari cara kerja sebuah sistem yang dibuat, sehingga dapat memberikan penjelasan dalam bentuk gambar. Penjelasan yang berupa gambar proses kerja sebuah sistem merupakan gambar dari diagram alur sistem yang akan dibuat. Tujuan dari pembuatan diagram alur adalah untuk mempermudah pembaca dan pembuat sistem itu sendiri untuk memahami langkahlangkah serta cara kerja sebuah sistem yang dibuat. 
Unitek : Jurnal Universal Teknologi

Vol. 14 No.1 Januari-Juni 2021

e-ISSN : 2580-2582, p-ISSN: 2089-3957

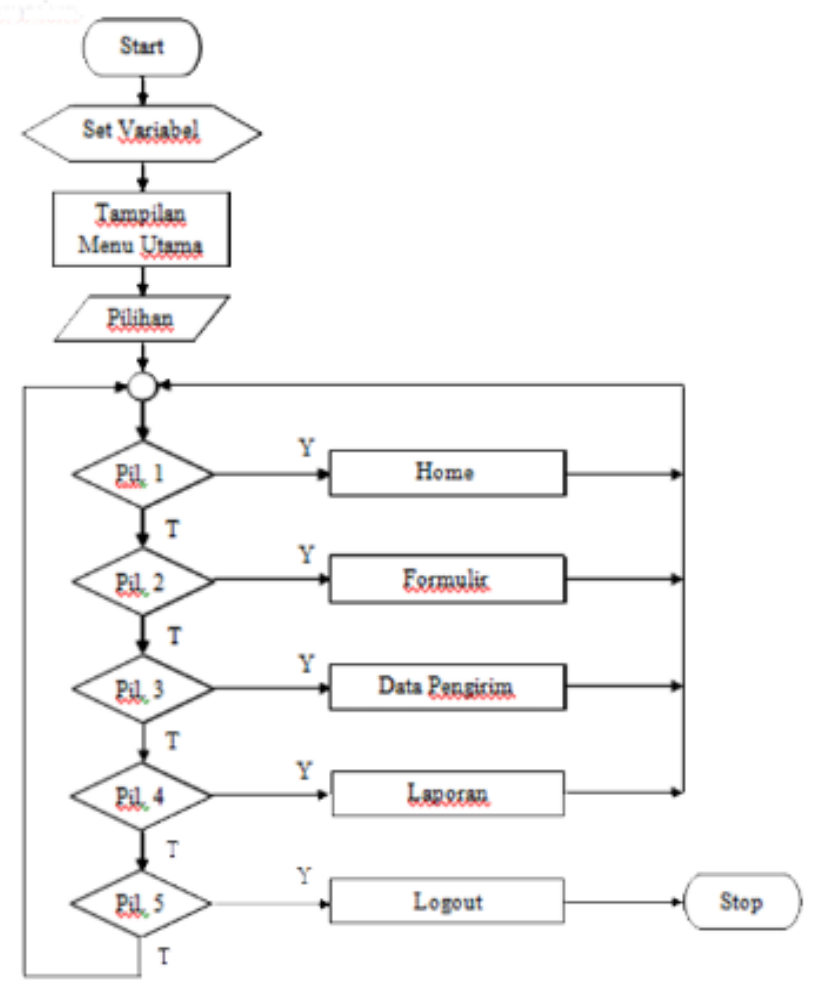

Gambar 3 Flowchart menu utama

Aplikasi ini dibuat agar lebih efisien dalam mendapatkan informasi tentang data shipper barang yang dibutuhkan oleh Counter JNE Bukit Kapur, oleh karena itu Aplikasi ini dibangun untuk mempermudah dalam proses penyampaian hasil pendataan Shipper Barang pada Counter JNE Bukit Kapur. Sistem ini didesain dari beberapa halaman untuk lebih memudahkan, penulis akan menampilkan pada sub bab di bawah ini:

\section{Halaman Login}

Adapun tampilan halaman utama Aplikasi Pengarsipan Shipper Barang pada Counter JNE Bukit Kapur dengan memasukkan username dan password yang benar.

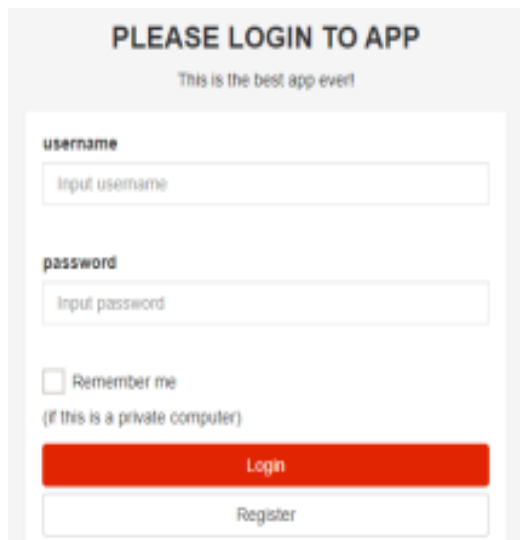

Gambar 4. Tampilan halaman login admin 


\section{Halaman Utama}

Berikut halaman utama Aplikasi Pengarsipan Shipper Barang pada Counter JNE Bukit Kapur sebagai media informasi untuk admin.

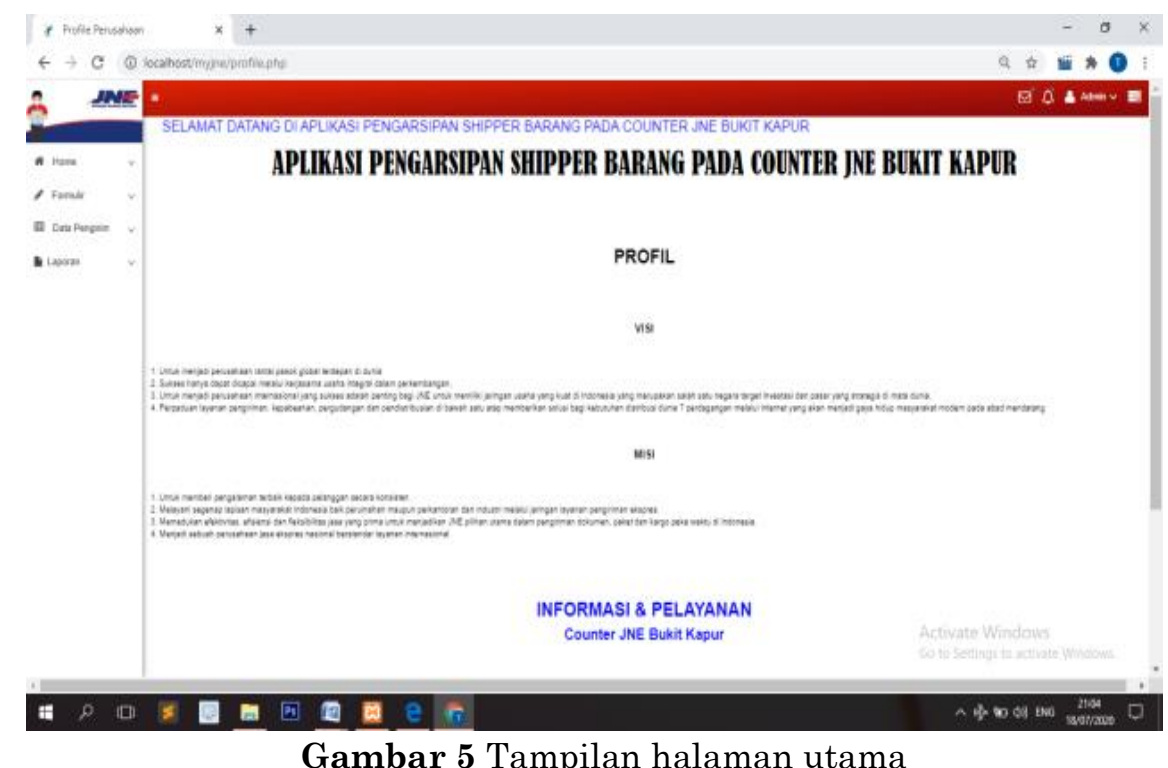

\section{Halaman input Data Pengirim}

Berikut tampilan halaman input Data Pengirim Aplikasi Pengarsipan Shipper Barang pada Counter JNE Bukit Kapur.

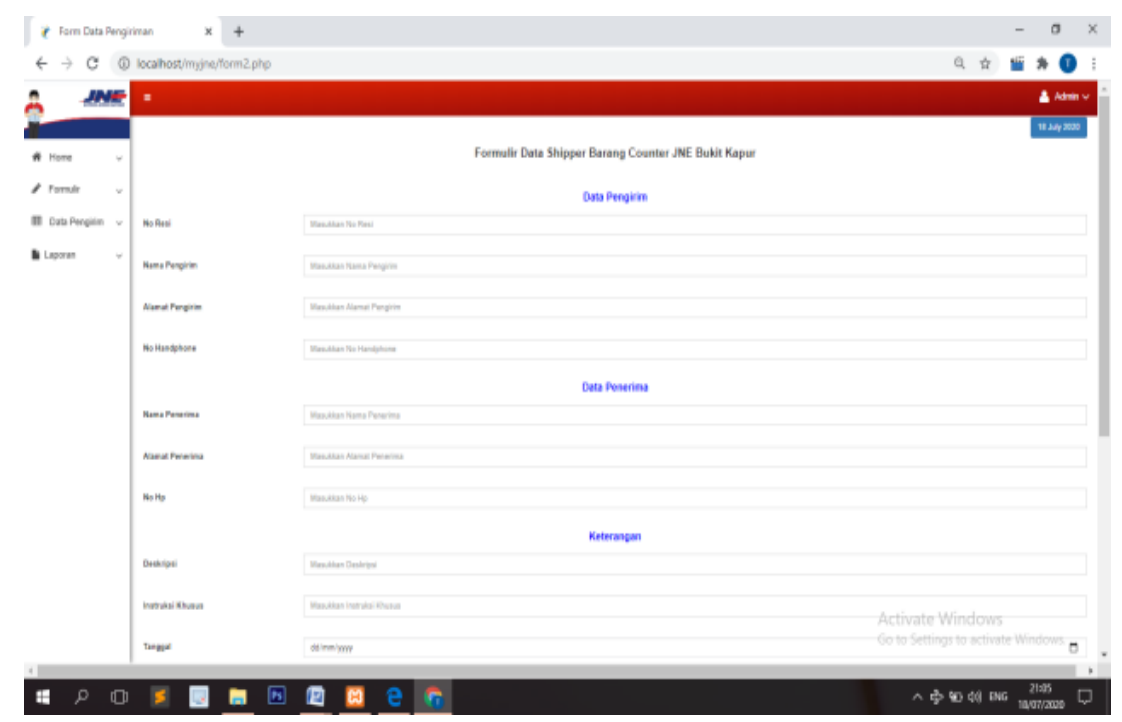

Gambar 6 Tampilan halaman input Data Pengirim

\section{Halaman Output Data Pengirim}

Berikut tampilan halaman output Data Pengirim Aplikasi Pengarsipan Shipper Barang pada Counter JNE Bukit Kapur. 
Unitek : Jurnal Universal Teknologi

Vol. 14 No.1 Januari-Juni 2021

e-ISSN : 2580-2582, p-ISSN: 2089-3957

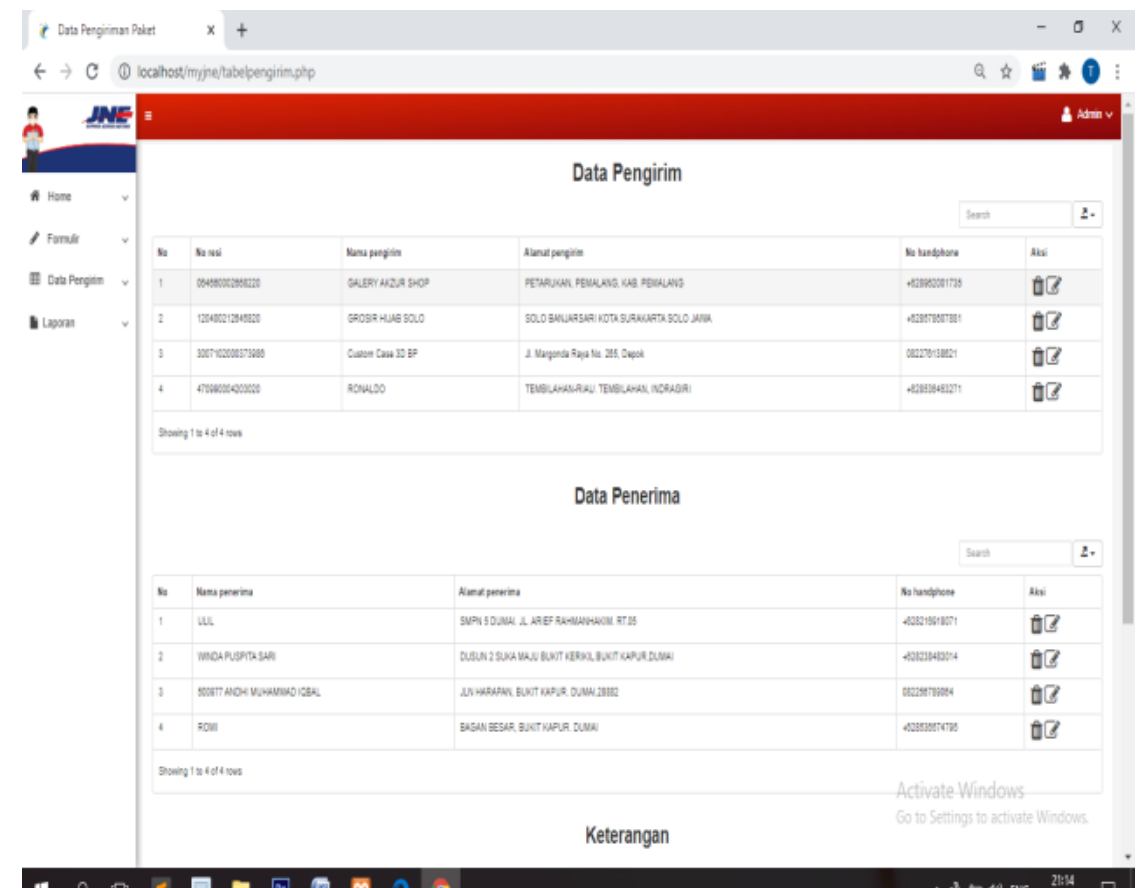

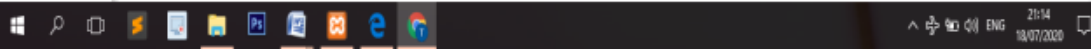

Gambar 7 Tampilan halaman output Data Pengirim

\section{Halaman Laporan Data Pengirim}

Berikut tampilan halaman laporan untuk data pengirim yang akan dicetak atau disimpan oleh admin.

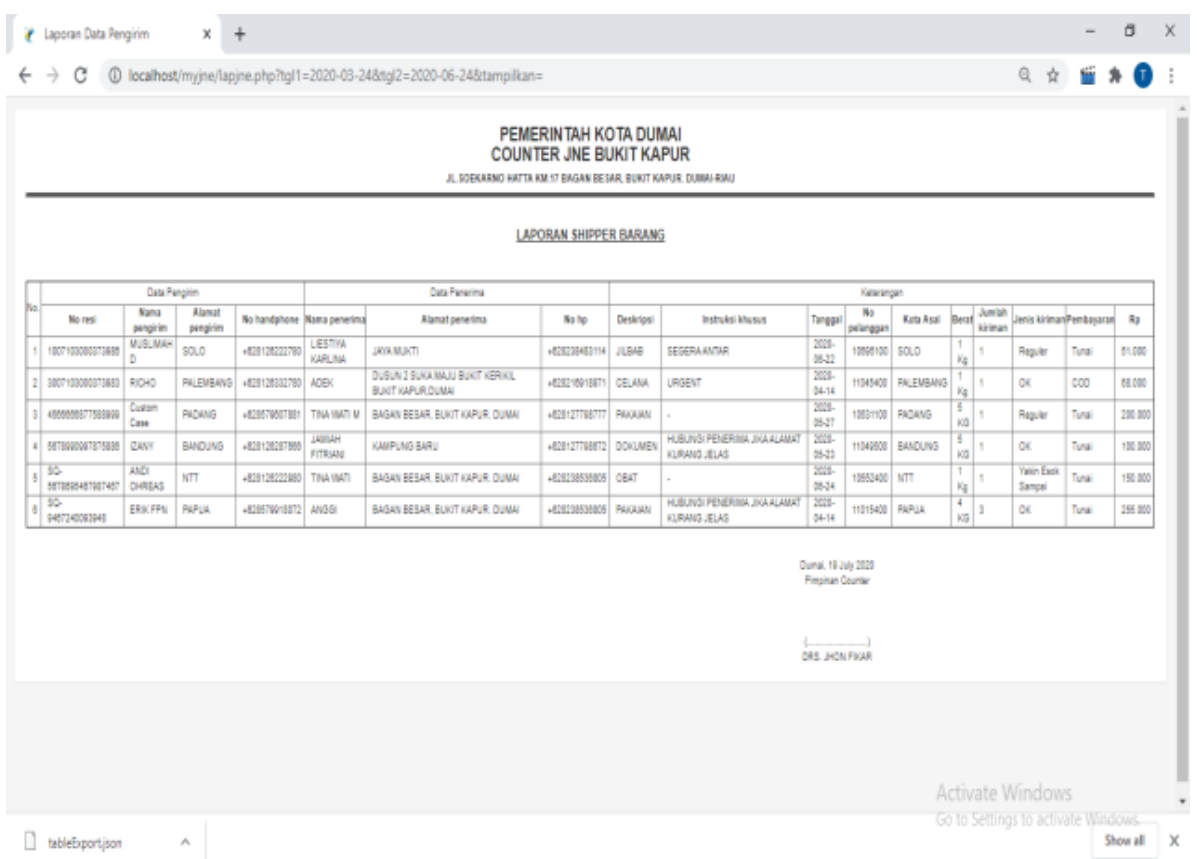

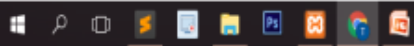

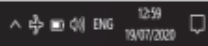

Gambar 8 Tampilan halaman Laporan Data Pengirim. 


\section{Simpulan}

Dari penelitian yang dilakukan, maka penulis dapat ditarik kesimpulan, bahwa Aplikasi pengarsipan shipper barang yang telah dibuat mempermudah pekerjaan admin dalam mengelola data barang milik shipper pada Counter JNE Bukit Kapur. Selain itu Aplikasi ini juga dapat mencetak laporan terperinci sehingga membantu admin dalam mengelola seluruh data shipper.

\section{Daftar Pustaka}

Andi A, (2011), "Sistem Informasi Manajemen Inventori Secara Online Menggunakan Framework Easy UI“, Politeknik Negeri Bengkalis.

Anhar. (2010). PHP \& MySql Secara Otodidak. Jakarta: PT Trans Media.

Dewi, I.K., Kusrini, Fatta, H.A. (2016). Analisis Dan Perancangan Sistem Informasi Perpustakaan STKIP Hamzanwadi Selong Dengan Menggunakan Togaf ADM. Jurnal Ilmiah DASI, 15(4), 20-25.

Dhanta, R. (2009). Pengantar Ilmu Komputer. Surabaya: INDAH.

Isa, I.G.T., Hartawan, G.P. (2017). Perancangan Aplikasi Koperasi Simpan Pinjam Berbasis Web (Studi Kasus Koperasi Mitra Setia). Jurnal Ilmiah Ilmu Ekonomi, 5(10), 139-151.

Listianto, F., Fauzi, Irviani, R., and Kasmi. (2017). Aplikasi E-Commerce Berbasis Web Mobile Pada Industri Konveksi Seragam Drumband Di Pekon Klaten Gadingrejo Kabupaten Pringsewu. J. TAM ( Technol. Accept. Model), 8(2), $146-152$.

Madcoms. (2016). Sukses Membangun Toko Online dengan PHP \& MySQL. Yogyakarta: Andi.

Nurhayati, A.N., Josi, A., and Hutagalung, N.A. (2018). Rancang Bangun Aplikasi Penjualan Dan Pembelian Barang Pada Koperasi Kartika Samara Grawira Prabumulih. J.Teknol. dan Inf., 7(2), 13-23.

Pahlevi, O., Mulyani, A., and Khoir, M. (2018). Sistem Informasi Inventori Barang Menggunakan Metode Object Oriented Di Pt. Livaza Teknologi Indonesia Jakarta. J. PROSISKO, 5(1), 27-35.

Rosa, A.S., dan Salahuddin, M. (2011). Modul Pembelajaran Rekayasa Perangkat Lunak (Terstruktur dan Berorientasi Objek). Bandung : Modula.

Sarosa dan Samiaji (2017). Metodologi Pengembangan Sistem Informasi. Jakarta: Indeks Jakarta.

Sholiq. (2010). Analisis dan Perancangan Berorientasi Objek. Bandung: Muria Indah.

Simangunsong, A. (2018). Sistem Informasi Pengarsipan Dokumen Berbasis Web. J. Mantik Penusa, 2(1), 11-19. 